\title{
A colonic metastasis from extrahepatic cholangiocarcinoma after removal of primary tumor: a case report and literature review
}

\author{
Xia Zheng ${ }^{1 \#}$, Wen-Tao Zhang ${ }^{2 \#}$, Jun Hu$^{2}$, Xiao-Feng Chen ${ }^{3,4}$ \\ ${ }^{1}$ Department of Oncology, The 81st Hospital Affiliated Nanjing University of Chinese Medicine, Nanjing 210001, China; ${ }^{2}$ Department of Oncology, \\ Nanjing Red Cross Hospital, Nanjing 210002, China; ${ }^{3}$ Department of Oncology, The First Affiliated Hospital of Nanjing Medical University, \\ Nanjing 210029, China; ${ }^{4}$ Department of Oncology, Pukou Branch Hospital of Jiangsu Province Hospital (Nanjing Pukou Central Hospital), Nanjing \\ 211800, China \\ "These authors contributed equally to this work. \\ Correspondence to: Jun Hu. Department of Oncology, Nanjing Red Cross Hospital, Nanjing 210001, China. Email: hujun1988115@126.com; \\ Xiao-Feng Chen. Department of Oncology, The First Affiliated Hospital of Nanjing Medical University, Nanjing 210029, China. \\ Email: 13585172066@126.com.
}

\begin{abstract}
Metastatic cholangiocarcinoma (CCA) to the gastrointestinal tracts has rarely been described in the literature. We report a 54-year-old male patient with radical resection of an extrahepatic CCA who underwent uncommon metastatic pattern. After a recurrence-free period of 2 years, an elevated CA199 initiated a CT scan, showing a tumor at the junction of rectum and sigmoid with enlarged lymph nodes around colon, mimicking a primary colon cancer. Histological diagnosis was adenocarcinoma, and the patient was treated with surgery as a primary colon cancer, but post-operative immunohistochemistry revealed the same pattern as the CCA. As colon is not the common organ for distant spread that makes some challenge to distinguish the colonic metastatic CCA between primary colon carcinoma. Biomarkers (CA 19-9), immunohistological and pathological features play an important role in distinguishing CCA from primary colon cancer. This case taught us a lesson how cancers can spread to unusual sites and mimic other tumor types, that may change the treatment and prognostication significantly.
\end{abstract}

Keywords: Cholangiocarcinoma (CCA); metastatic/secondary colon adenocarcinoma; immunohistochemistry; misdiagnosis

Submitted Sep 02, 2019. Accepted for publication Jan 14, 2020.

doi: $10.21037 /$ cco.2020.01.08

View this article at: http://dx.doi.org/10.21037/cco.2020.01.08

\section{Introduction}

Cholangiocarcinoma (CCA) is a high degree of malignant cancer arising from anywhere from the intrahepatic to the extrahepatic biliary epithelium. Clinically, most patients with CCA are advanced stage when diagnosed due to the highly aggressive ability. Only a few cases are diagnosed at the early stage which can be treated by surgical resection while majority of them will recurrent or metastasize to other organs during a short time after operation. Lungs, adrenal glands, liver as well as lymph nodes are the common metastatic sites via the lymphatics or vascular. Metastatic CCA of the colorectum is rare with only sporadic cases reported until now. Here we present a case of colonic metastatic adenocarcinoma in a patient with 2-year history of extrahepatic CCA radical resection.

\section{Case presentation}

A 54-year-old male patient underwent the hepatic left lobe and tumor resection after a hepatic portal tumor with intrahepatic bile ducts prominence found by CT scan in January 2015 (Figure 1). The surgical specimens contained a solitary gray mass located at hepatic portal, $3 \times 2 \times 2 \mathrm{~cm}$ in size. Cancer tissue infiltrated ductus hepaticus communis, left and right hepatic ducts, hepatic tissue. Pathological 
results showed a well differentiated adenocarcinoma (Figure 2). There was one in two lymph nodes metastasis around the liver with microvascular and nerve invasion.

The patient had no signs of recurrence over the next 2 years until a high level of CA19-9 $(162.36 \mathrm{U} / \mathrm{mL})$ was detected in January 2017. A contrast-enhanced CT showed a submucosa eminent lesion at the junction of rectum and sigmoid with enlarged lymph nodes around colon (Figure 3). Examination of the colonoscopic biopsy revealed adenocarcinoma. The patient received colon tumor resection and lymph nodes dissection after considered as a case of colonic primary adenocarcinoma. The final pathological results showed a well differentiated adenocarcinoma and the mass mainly existed serosa with infiltrating to submucosa and mucosa (Figure 2).

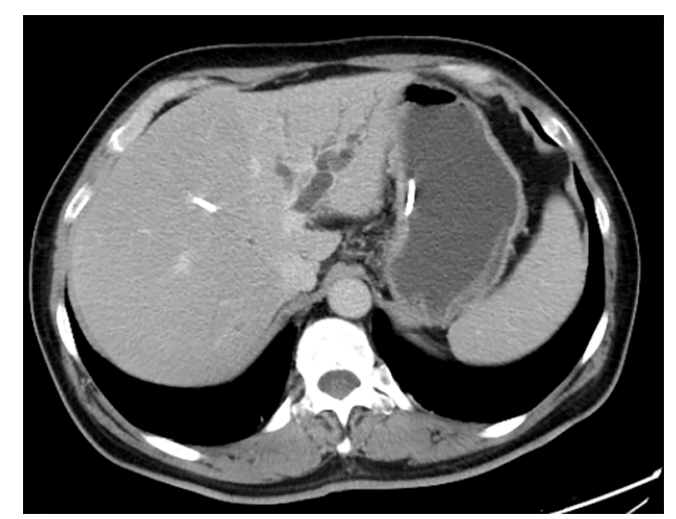

Figure 1 Contrast-enhanced CT scan before the first and second operation. A hepatic portal tumor with intrahepatic bile ducts prominence.
Immunohistochemical staining was positive for cytokeratin (CK)-19 (strong), CK-20 (weak) and villin (weak) while negative for CK-7 and CDX-2, which were consistent with the hepatic portal carcinoma resected 2 years ago (Figure 2). At last, the colonic tumor was diagnosed metastasis from hepatic portal CCA according to the expression of the above molecular markers and pathological results.

The disease progressed 1 month later, which was convinced by an enlarged anterior pancreatic lymph node in CT scan. The patient refused to receive chemotherapy and he was giving only support care. In June 2016, the patient died due to broader spreading of cancer.

\section{Discussion and conclusions}

Most of colonic tumors originate from colonic epithelium with the feature of metastasis to other organs such as liver and hepatic portal lymph nodes. The reported cases of metastatic colonic malignancy from liver or bile ducts were extremely rare. CCA as a kind of cancer arising from biliary epithelium can be treated with resection during early stage but easily recurrent. Liver, lung, and lymph nodes are common metastatic sites instead of colon (1). Only seven cases of colonic metastasis CCA have been described on the literature so far. Therefore, this pattern of distant metastasis has been less understood. Initially, Wakahara reported a male patient with intrahepatic cholangiocarcinoma (ICC) with sigmoidectomy metastasis in 2005 (2). The other six cases were reported in the year of 2010, 2011, 2012, and 2016, respectively (Table 1) (3-8). The mean age of these patients is 63.6 (range, 57-76). Five of them were diagnosed
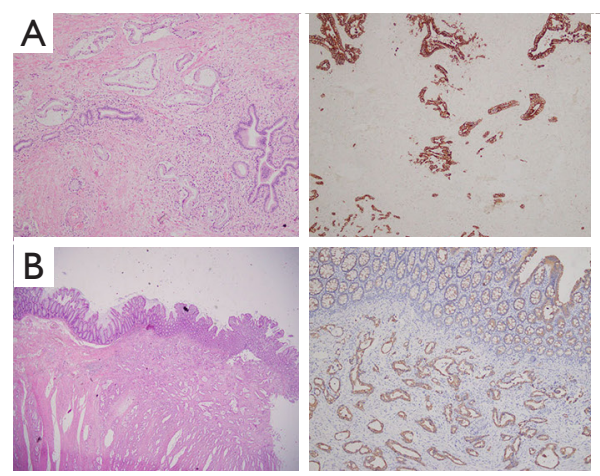
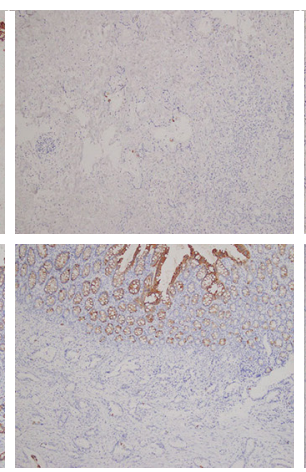
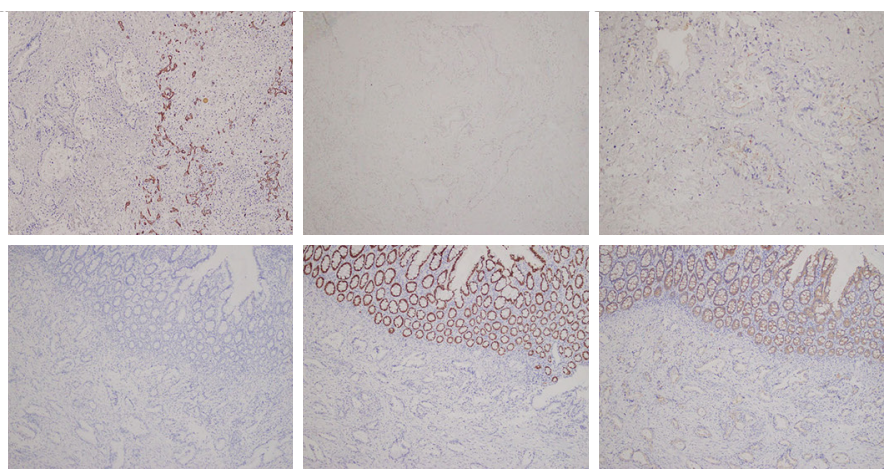

Figure 2 Pathological and immunohistochemical result after operations. A well differentiated adenocarcinoma with positive staining of CK 19 (strong), CK-20 (weak) and villin (weak) while negative staing of CK-7 and CDX-2 in liver (A) and colon (B) tumor mass (H\&E, 10×10). 


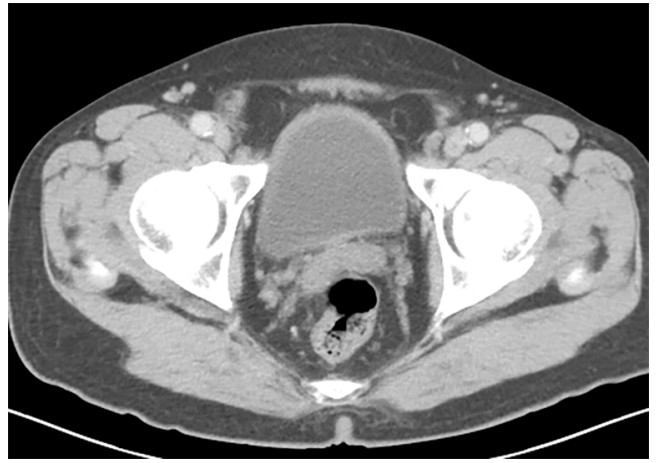

Figure 3 A submucosa eminent lesion at the junction of rectum and sigmoid with enlarged lymph nodes around colon. with ICC, and two with extrahepatic cholangiocarcinoma (ECC). Four in seven patients confirmed to be colonic metastatic CCA when the primary cancer diagnosed. Three cases metastasized to colon after the primary cancer resection for 5, 6 years and 15 months respectively, which is similar to current patient.

Based on the features of these limited cases, we identified some differences between colonic primary cancer and metastatic disease. Endoscopically, the secondary colonic cancer lesions consist of multiple discrete submucosal nodularity with intact mucosa. The submucosal infiltration by metastatic cancer often forms stricture, which is

Table 1 Literature review of cholangiocarcinoma with gastrointestinal spread

\begin{tabular}{|c|c|c|c|c|c|c|c|}
\hline $\begin{array}{l}\text { Author/reported } \\
\text { years }\end{array}$ & Age & Gender & Clinic history & $\begin{array}{c}\text { Biliary } \\
\text { site }\end{array}$ & Endoscopic result & Biliary IHC & $\begin{array}{c}\text { Colonic } \\
\text { mass IHC }\end{array}$ \\
\hline $\begin{array}{l}\text { Wakahara } \\
\text { et al., } 2005 \text { (2) }\end{array}$ & 62 & Male & $\begin{array}{l}\text { Abdominal imagines showed } \\
\text { a hepatic tumor and a } \\
\text { submucosal mass at the } \\
\text { sigmoid colon in a patient } \\
\text { with an increased CAE }\end{array}$ & ICC & $\begin{array}{l}\text { The mucosa over the tumor was } \\
\text { accompanied by telangiectasis }\end{array}$ & $\begin{array}{l}\text { CK7+, } \\
\text { CK20+ }\end{array}$ & CK7+, CK20+ \\
\hline $\begin{array}{l}\text { Fujii et al., } \\
2010(4)\end{array}$ & 59 & Female & $\begin{array}{l}\text { Biliary colic with CBD stricture } \\
\text { diagnosed with ECC and } \\
\text { concomitant hematochezia }\end{array}$ & ECC & $\begin{array}{l}\text { multiple depressed erythematous } \\
\text { lesions and mucosal retraction } \\
\text { were found in the proximal } \\
\text { transverse and sigmoid colon }\end{array}$ & Unavailable & $\begin{array}{l}\text { CK7+, CK20-, } \\
\text { CDX-2- }\end{array}$ \\
\hline $\begin{array}{l}\text { Tokodai et al., } \\
2012(6)\end{array}$ & 57 & Male & $\begin{array}{l}\text { Intestinal obstruction was } \\
\text { found in a patient with } 6 \text { years } \\
\text { history of ICC resection }\end{array}$ & ICC & $\begin{array}{l}\text { An intestinal obstruction at the } \\
\text { level of the hepatic flexure with } \\
\text { an edematous ulcer-like lesion on } \\
\text { the mucosal surface }\end{array}$ & Unavailable & $\begin{array}{l}\text { CK7+, } \\
\text { CK20+ } \\
\text { (weekly) }\end{array}$ \\
\hline $\begin{array}{l}\text { Vabi et al., } \\
2016(7)\end{array}$ & 61 & Female & $\begin{array}{l}\text { Imaging study found } \\
\text { intrahepatic bile ducts } \\
\text { prominence without mass } \\
\text { lesions and diffuse colonic } \\
\text { thickening without mass } \\
\text { lesions or obstruction }\end{array}$ & ECC & $\begin{array}{l}\text { Multiple discrete, hard } \\
\text { submucosal nodularities } \\
\text { throughout the transverse and } \\
\text { ascending colon }\end{array}$ & Unavailable & $\begin{array}{l}\mathrm{CK} 7+ \\
\text { CK20- }\end{array}$ \\
\hline
\end{tabular}

ICC, intrahepatic cholangiocarcinoma; ECC, extrahepatic cholangiocarcinoma; CBD, common bile duct. 
Table 2 Immunohistochemical markers for primary colon and bile duct tumors

\begin{tabular}{lccccc}
\hline \multirow{2}{*}{ Critical markers } & \multicolumn{3}{c}{ Colon } & & \multicolumn{2}{c}{ Bile duct } \\
\cline { 2 - 5 } \cline { 3 - 6 } CDX-2 & Specificity (\%) & Sensitivity (\%) & 93.9 & Specificity (\%) & Sensitivity (\%) \\
CK-7 & 86.2 & 16.4 & 23.2 & 13.0 \\
CK-20 & 14.3 & 87.8 & 72.8 & 73.9 \\
\hline
\end{tabular}

unlike to primary colon cancer originating from mucosa with radial extension assuming bleeding ulceration or loss of lobulation (9). Histopathological examination often reveals adenocarcinoma. Tumor mass mainly exists in the subserosa and colonic wall with infiltrating to submucosa and mucosal, which is contrary to primary cancer rising from mucosa with outward spreading. Immunohistochemistry is the most reliable feature to distinguish colonic primary adenocarcinoma from metastatic CCA to colon. However, there is no specific or sensitive protein to confirm the origin site. Usually, CK-7 positive with CK-20 negative or weakly positive suggests the tumor rising from pancreaticobiliary (10) (Table 2). Similarly, CK-19 strongly positive with CDX-2 negative also indicates the tumor comes from biliary tract instead of colorectum. However, these markers should be read and judged comprehensively.

It is difficult to distinguish colonic recurrence of CCA from a primary colon cancer in this patient based on the preoperative clinical, endoscopic and radiologic features. That is because primary colon cancer occurs more commonly than secondary one. After the second operation, we diagnosed colon metastasis from CCA for the following reasons. Firstly, there were no other primary site of metastatic adenocarcinoma was found by gastrointestinal endoscopy and CT scan. Secondly, the cancer mass infiltrated heavily on colonic wall than mucous, which eliminate the tumor arose from later. Thirdly, the colonic tumor expressed CK19 strongly positive and CDX-2 negative, suggesting the biliary tract origin instead of colon. Last, the colonic mass had similar immunohistochemical characteristics to the primary CCA.

In a conclusion, the cases of colonic metastatic CCA are extremely rare and easily misdiagnosed as a second primary colon adenocarcinoma. In retrospect, this signifies the importance of differential diagnosis immunohistochemistry and other modalities to avoid unnecessary over treatment.

\section{Acknowledgments}

Funding: None.

\section{Footnote}

Conflicts of Interest: All authors have completed the ICMJE uniform disclosure form (available at http://dx.doi. org/10.21037/cco.2020.01.08). The authors have no conflicts of interest to declare.

Ethical Statement: The authors are accountable for all aspects of the work in ensuring that questions related to the accuracy or integrity of any part of the work are appropriately investigated and resolved.

Open Access Statement: This is an Open Access article distributed in accordance with the Creative Commons Attribution-NonCommercial-NoDerivs 4.0 International License (CC BY-NC-ND 4.0), which permits the noncommercial replication and distribution of the article with the strict proviso that no changes or edits are made and the original work is properly cited (including links to both the formal publication through the relevant DOI and the license). See: https://creativecommons.org/licenses/by-nc-nd/4.0/.

\section{References}

1. Lee YT, Geer DA. Primary liver cancer: pattern of metastasis. J Surg Oncol 1987;36:26-31.

2. Wakahara T, Tsukamoto T, Kitamura S, et al. Metastatic colon cancer from intrahepatic cholangiocarcinoma. J Hepatobiliary Pancreat Surg 2005;12:415-8.

3. Izzo F, Piccirillo M, Albino V, et al. Case report: appearance of an intestinal metastasis from intrahepatic cholangiocarcinoma occurring 5 years after resection 
of the primary tumor. Eur J Gastroenterol Hepatol 2010;22:892-4.

4. Fujii K, Goto A, Yoshida Y, et al. Gastrointestinal: Transmural colonic metastasis arising from primary cholangiocarcinoma. J Gastroenterol Hepatol 2010;25:1329.

5. Mimatsu K, Oida T, Kawasaki A, et al. Long-term survival after resection of mass-forming type intrahepatic cholangiocarcinoma directly infiltrating the transverse colon and sequential brain metastasis: Report of a case. Surg Today 2011;41:1410-3.

6. Tokodai K, Kawagishi N, Miyagi S, et al. Intestinal obstruction caused by colonic metastasis from intrahepatic cholangiocarcinoma 6 years after removal of the primary tumor: report of a case. Surg Today 2012;42:797-800.

Cite this article as: Zheng X, Zhang WT, Hu J, Chen XF. A colonic metastasis from extrahepatic cholangiocarcinoma after removal of primary tumor: a case report and literature review. Chin Clin Oncol 2020;9(2):21. doi: 10.21037/cco.2020.01.08
7. Vabi BW, Carter J, Rong R, et al. Metastatic colon cancer from extrahepatic cholangiocarcinoma presenting as painless jaundice: case report and literature review. $\mathrm{J}$ Gastrointest Oncol 2016;7:E25-30.

8. Niazi A, Saif MW. Colon Mass as a Secondary Metastasis from Cholangiocarcinoma: A Diagnostic and Therapeutic Dilemma. Cureus 2016;8:e707.

9. Hong SP. Malignant Tumors in Colon. In: Chun JH, Yang KS, Choi MG, editors. Clinical Gastrointestinal Endoscopy: A Comprehensive Atlas. New York: Springer Dordrecht Heidelberg London New York, 2014:475-98.

10. Tot T. Cytokeratins 20 and 7 as biomarkers: usefulness in discriminating primary from metastatic adenocarcinoma. Eur J Cancer 2002;38:758-63. 